\title{
ASPECTS CONCERNING THE PHOTO- AND BIODEGRADATION OF BENZOTHIAZOLES IN AQUATIC COMPARTMENT
}

\author{
A.-M.Delort ${ }^{1}$, P.Besse ${ }^{1}$, G.Mailhot ${ }^{1}$, M.Sancelme ${ }^{1}$, B.Combourieu ${ }^{1}$, Ch.Chorao ${ }^{1}$, O.Covaliova ${ }^{2}$, \\ V.Covaliov ${ }^{2}$, A.Bunescu ${ }^{3}$, I.Dragalin ${ }^{3}$, A.Cincilei ${ }^{4}$, S.Tolocichina ${ }^{4}$ \\ ${ }^{1}$ Blaise Pascal University, Clermont-Fd, France \\ ${ }^{2}$ CSChAsiE, State University of Moldova, 60 Mateevici Street, Moldova State University, Faculty of Chemistry and Chemical \\ Technology,Bl.IV, of.115, tel/fax:+37322.577707,olga196cov@yahoo.com \\ ${ }^{3}$ Institute of Chemistry of ASM, Chisinau, Moldova \\ ${ }^{4}$ Institute of Microbiology and Biotechnology of ASM, Chisinau, Moldova
}

\begin{abstract}
With the scope to provide complete decomposition of benzothiazoles in water environment, two approaches have been applied including the photocatalytic and biodegradation processes. A new type of continuousaction flow-through photocatalytic reactor was developed, in which it is possible to combine the homogeneous and heterogeneous destruction of refractory organic pollutants. The interactions between the different components of the aminobenzothiazole-containing system under the conditions of photo- and biodegradation (light, iron, free and immobilized bacterial strain Rhodococcus rhodochrous) were analysed. The combined systems "Fe \pm light + Rh.rhodochrous" are more effective than simple systems.
\end{abstract}

Keywords: Photocatalysis, biodegradation, Fenton reagent, immobilized cells, dynamic reactor, active radicals, benzothiazoles, iron, Rhodococcus sp.

\section{Introduction}

The contamination of water due to the industrialization of the society will still remain to be a major ecological problem of this century. Xenobiotics and their degradation products can be accumulated in water and soil, thus causing the changes, often irreversible, in the ecosystems. However, due to the large diversity of pollutants and the increasing amounts of discharges in the environment, conventional methods are not sufficient. That is why scientists give special importance to the photocatalytic [1,2] and biological detoxication processes, capable to provide an almost complete degradation of the toxicant $[3,4]$.

Benzothiazole (BT) and its derivatives (BTs) are among the rived anthropogenic pollutants and are attributed to persistent organic compounds with carcinogenic properties [5,6]. BTs are used in the production of pharmaceutical preparations, as catalysts in rubber vulcanization and leather processing, finishing metal treatment, in paper-manufacturing, as herbicides, antialgae agent, and fungicides to protect the wood products, as corrosion inhibitors and for other scopes $[7,8]$. Because of such broad distribution, BTs are present not only in the industrial, but in the municipal waste water as well.

The elimination of benzothiazole derivatives is extremely difficult when biotic or abiotic processes are used alone, so we have proposed to combine both photo- (using Fe as photo-activator) and biodegradation (using free and immobilized microorganisms) processes for the decontamination of water, and to study the physical and chemical factors affecting the degradation of BTs with active strains. This approach is completely new. To perform the efficient photo-degradation process, a new design of the integrated reactor was elaborated. Also, considering an importance of microbiological detoxification, our purpose was to select the strains that use BTs as the only source of nitrogen, carbon and energy, and to study the products of their microbial transformation.

\section{The analysis of Experimental Results}

Photodegradation: The photocatalytic processes were studied in the especially developed reactor (MD Patent Application Nr.2007-0190), shown on Fig.1. The reactor involves the case in which UV lamps (2) and U-shaped flow-through quartz cylinders (1) are inserted, along with the cleaning system for their inner surface with brushes (3), connected to the moving mechanism (5) and electric motor (4). The up-down movement of brushes inside the quartz cylinders provides the permanent cleaning of glass walls from the suspensions particles, and intensifies the massexchange.

The reactor is equipped with magnetic device (6) to enrich the introduced air with oxygen. The enrichment process is based on the fact that oxygen, possessing high paramagnetic properties and positive magnetic perceptibility, is attracted to the tube walls in the magnetic field applied. The ring electromagnets are installed outside the device. Abnormal paramagnetic properties of oxygen molecules are explained by the presence of unpaired electrons. Therefore, molecular oxygen, unlike the other air components, will be selectively attracted into the magnetic field zone, near the cylinder walls. Meantime, the low-oxygenated portion of the air from the central part of the tube is emitted outside with the help of the regulating valve. The air portion enriched with oxygen is introduced into the reactor with treated solution. 
A

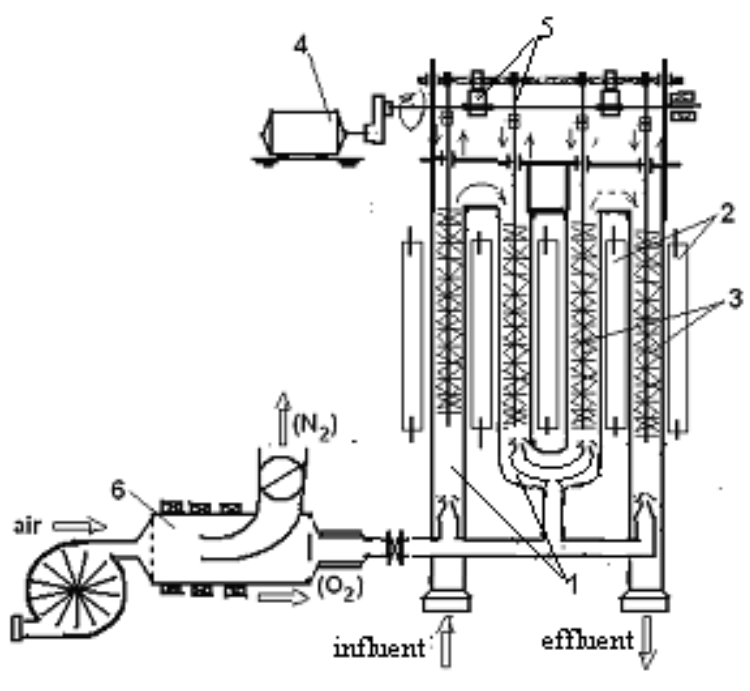

$\mathrm{B}$

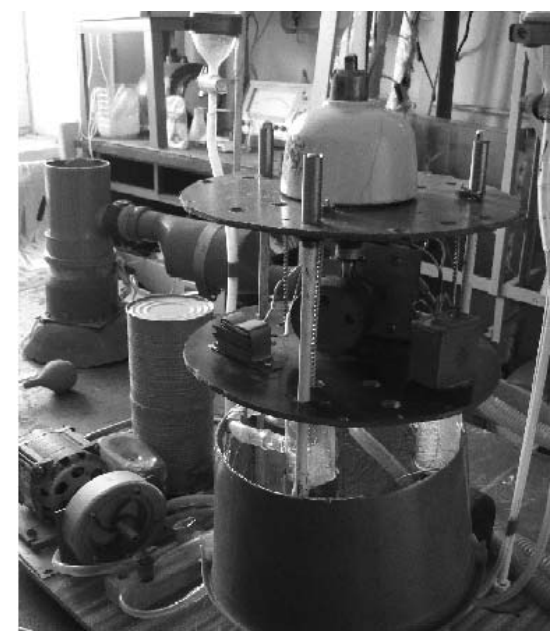

Fig.1. The scheme (A) and general view (B) of dynamic reactor for photocatalytic destruction of refractory organics

As can be seen from Fig.2, chromatograms of initial OBT water solutions have the retention peak within 5,85 $\mathrm{min}$, however, after the treatment, the intensity of this peak decreases from 125 to $20 \mathrm{mAU}$, which fact testifying on the destruction processes proceeding. At the same time, new peaks appear, and their intensity increases at the retention time from 0,65 to 3,885 min, which fact evidences the formation of intermediate destruction products.

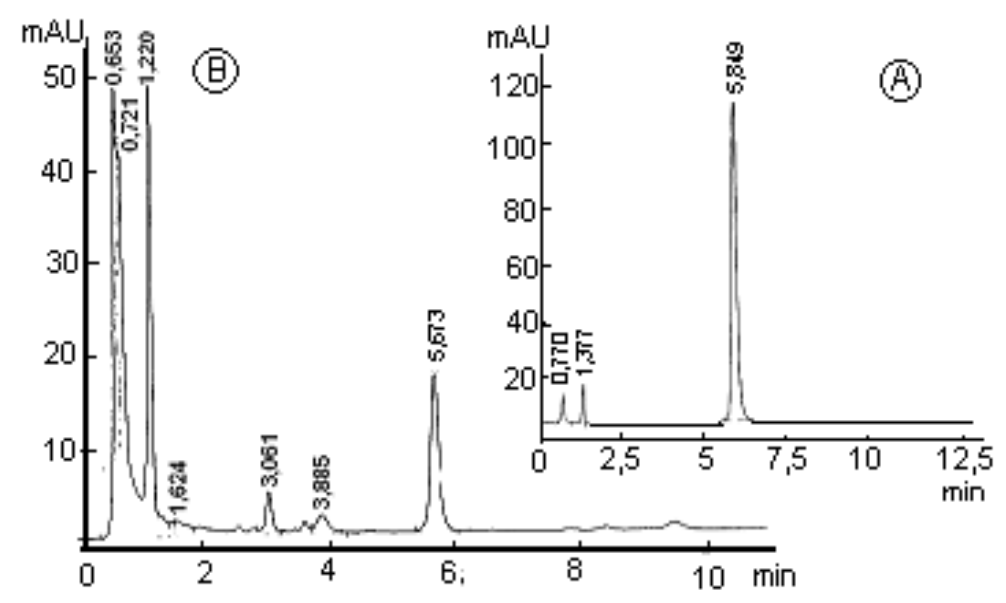

Fig. 2. Chromatograms obtained in the OBT water solutions prior to the treatment (A) $\left(\left[\mathrm{OBT}_{\text {intital }}=0,5 \mathrm{mMol}, \mathrm{pH}=7,0, \mathrm{t}=25^{\circ} \mathrm{C}\right)\right.$, and after the Fenton/UV-treatment (B) within $0,5 \mathrm{H}$.

As follows from Fig.3, the intensity of the destructive photocatalytic processes increases in the presence of either $\mathrm{TiO}_{2}$ or Fenton reagent, when $70-80 \%$ destruction is reached (curves 2 and 3), and essentially increases during the homogeneous-heterogeneous process, at the simultaneous presence of these two factors (curve 4), when the mineralization is reached within 130-150 min. Introducing of oxygen-enriched air into the reaction bulk also promotes this process (curve 5).

According to some researchers [2], intermediates are forming during the transformation process under the UVirradiation of OBT solution, up to their complete mineralization, following the scheme:

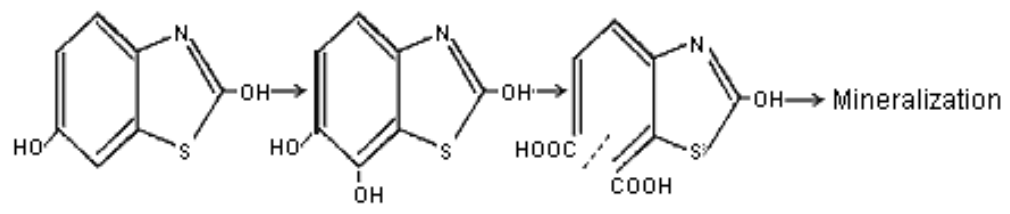


Thus, at the first stage, photocatalytical oxidation occurs step-by-step with OG-group adjoining to the 4th position of benzene ring, with further formation of acid groups and primary ring breakage. With the increase of treatment time and $\mathrm{H}_{2} \mathrm{O}_{2}$ concentration to $5 \mathrm{mMol}$ and higher, the rate of these processes increases essentially.

The mechanism of photocatalytic processes thus proceeding is associated with that the hydrogen peroxide molecules, due to the disproportioning reactions under the action of iron (II) and (III) ions and under the conditions of redox-photocatalysis, will generate a series of active radicals, specifically $\mathrm{OH}^{\bullet}-, \mathrm{OH}_{2}{ }_{2}$ and $\mathrm{O}_{2}{ }^{\bullet}$. Besides, due to the strong UV-irradiation under the wavelengths $180-300 \mathrm{~nm}$, water molecules radiolysis is also probable, following the reaction scheme: $\mathrm{H}_{2} \mathrm{O}+\gamma$-rays $\rightarrow \mathrm{OH}^{\bullet}+\mathrm{e}_{\mathrm{aq}}$. The hydrated electron $\left(\mathrm{e}_{\mathrm{aq}}\right)$ thus formed interacts with hydrogen peroxide, also forming the active radicals: $\mathrm{e}_{\mathrm{aq}}+\mathrm{H}_{2} \mathrm{O}_{2} \rightarrow \mathrm{OH}^{-}+\mathrm{OH}^{\bullet}$. The active radicals are the strong oxidizers in water solutions, and contribute to the hydrolytic decomposition of the complex molecular structures of organic compounds, thus making easier the running of further biochemical processes.

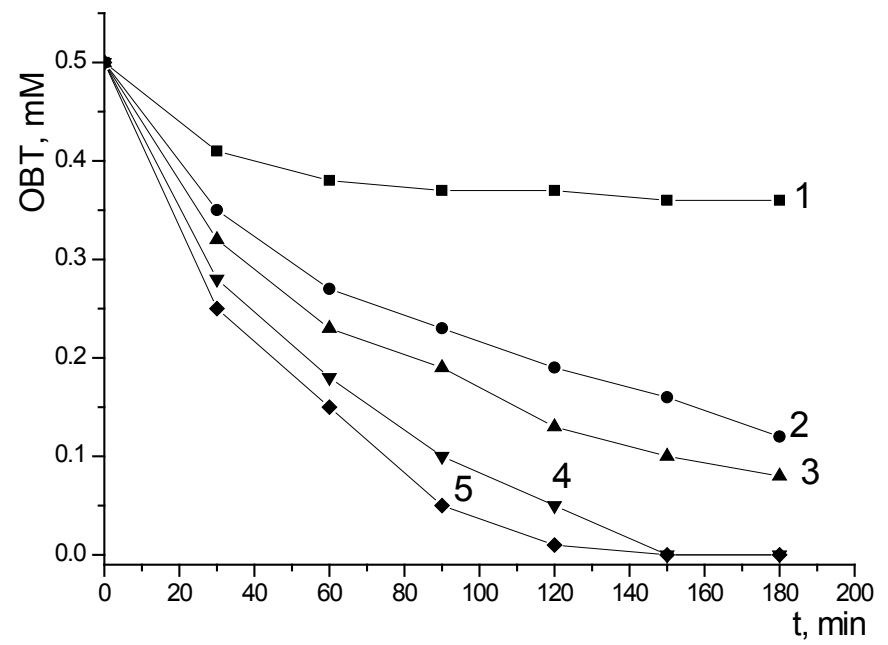

Fig. 3. Change in OBT concentration with time under the various conditions: 1 - $\mathrm{PTOF}+$ light; $2-\mathrm{TiO}_{2}+$ light; 3 - Fenton +light; 4- Fenton $+\mathrm{TiO}_{2}+$ light; 5 - Fenton $+\mathrm{TiO}_{2}+$ air $/ \mathrm{O}_{2}+$ light

$\mathrm{OH}^{\bullet}$ and $\mathrm{OH}^{\bullet}$, radicals possess high free negative energy $(263 \mathrm{~kJ} / \mathrm{mol})$, therefore they thermodynamically exert high oxidation reactivity towards the organic substances They oxidize the organic molecules following the hydrogen atom detachment mechanism, with the formation of water molecule: $\mathrm{RH}+\mathrm{OH}^{\bullet} \rightarrow \mathrm{R}^{\bullet}+\mathrm{H}_{2} \mathrm{O} \cdot \mathrm{O}_{2}{ }^{-}$radical possesses high reactivity both as oxidizer and reducer, thus it readily reduces the organic compounds with the acceptor properties.

$\mathrm{TiO}_{2}$ due to its strong photocatalytic properties is among the best materials used for the decomposition of organic substances. With the decrease of its particle size, their specific surface will increase, and thus the photoactivity increases. There are three types of $\mathrm{TiO}_{2}$ crystalline structure: (1)-anatase, (2)-ruthyl and (3)- brukite. An interval between the zones for anatase is 3,2 eV, for ruthyl - 3,02 eV, for brukite - 2,96 eV. The photocatalytic properties of $\mathrm{TiO}_{2}$ which cause the formation of free radicals oxidizing the organics, can be explained on the base of its electronic levels zonal structure [9].

In the Ti atom the electron levels $4 s^{2}$ and $3 d^{2}$ are completed, while in oxygen atom $-2 s^{2}$ and $2 p^{4}$. In the $\mathrm{TiO}_{2}$ molecule Ti ions are within the distorted octaedron and have electron configuration $\mathrm{Ti}^{4+}\left(3 \mathrm{~d}^{0}\right)$. The valence $\mathrm{zone}$ in $\mathrm{TiO}_{2}$ is mainly composed of oxygen 2p-orbitals, hydrolyzed with 3d-state of $\mathrm{Ti}$ [10]. Once $\mathrm{TiO}_{2}$ is subjected to UV-irradiation, electrons from valence zone $\left(e^{-}\right)$are exited and pass into the conductivity zone, forming the holes $\left(h^{+}\right): \mathrm{TiO}_{2}+h v \rightarrow$ $\mathrm{TiO}_{2}\left(e^{-}+h^{+}\right)$.

Thus, the light with the wavelength of $l<385 \mathrm{~nm}$, exites the electron and causes its transfer from the valance zone to the conductivity zone, forming the electron-hole pair. During the photocatalysis, two reagents can be adsorbed simultaneously on the $\mathrm{TiO}_{2}$ surface, and can be reduced and oxidized under the efficient light adsorption $(h v>=\mathrm{Eg})$. The capacity of electron transfer from the conductivity zone to adsorbed particle (acceptor) depends on the energy zone position of semiconductor and the redox potential of sorbate.

When the adsorbed pairs represent water and dissolved oxygen $\left(\mathrm{H}_{2} \mathrm{O} / \mathrm{O}_{2}\right)$, then water is oxidized with the positive holes and is splitted forming ${ }^{\circ} \mathrm{OH}$ and $\mathrm{H}^{+}$. As oxygen is an easily reducing substance, its reduction with photoelectron within the conductivity zone yields the generation of ' $\mathrm{O}_{2}^{-}$superoxide-radical anions. In their turn these will react with $\mathrm{H}^{+}$, generating ' $\mathrm{HO}_{2}$ dioxide hydrogen-radical. Resulting from the subsequent collisions with electron, $\mathrm{HO}_{2}^{-}$, hydrogen dioxide-radical is formed, and then the formation of hydrogen ion and $\mathrm{H}_{2} \mathrm{O}_{2}$ is possible. The above described reactions chain result in the formation of reactive oxygen-containing species, such as $\mathrm{H}_{2} \mathrm{O}_{2},{ }^{\text {' }} \mathrm{O}_{2}$ ' and ' $\mathrm{OH}$ hydroxyl-radical. 
The schematic representation of the specific photocatalytic processes which proceed on the surface of semiconducting metal oxides is shown on Fig.4.

Our experiments with pilot reactor shown on Fig.1 have confirmed that using the combination of homogeneous and heterogeneous photocatalytic treatment (i.e. simultaneous introducing of Fenton reagent and $\mathrm{TiO}_{2}$ ) of water systems containing the refractory organics, makes it possible to increase the intensity of destruction processes. However, as the photocatalytic process described is power-consuming, it was of practical interest to investigate the combination of this process with the microbial degradation of organic pollutants, which would not require energy consumption and would permit to improve the technological reliability of the destruction process.

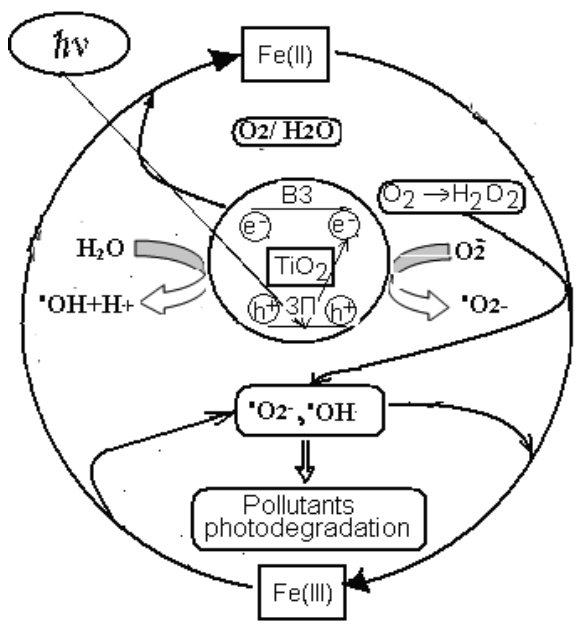

Fig. 4. The main processes proceeding during the photocatalytic redox-cycle in the combined system Fenton reagent $-\mathrm{TiO}_{2}-\mathrm{UV}$.

Biodegradation: As already known from the literature, benzothiazole derivatives are very recalcitrant and difficult to degrade. Only a few Rhodococcus isolates have been shown to degrade some BTs as pure culture [4]. With the scope to develop the combined photo- and biological technologies for decontamination of waste water, we selected some indigenous microbial strains that use the BTs pollutants as the only source of nitrogen, carbon and energy and studied the products of microbial transformation.

For the search of active microorganisms, a large number of experiments with the strains of soil fungi and bacteria - heterocyclic compounds destroyer (sim-triazine, acilalanine, and sulfonylurea) have been performed. Positive results were obtained when: 1) nitrogen salt was removed from the mineral medium; 2) xenobiotic concentration was reduced to $50 \mathrm{mg} / \mathrm{L}$ for BT and $100 \mathrm{mg} / \mathrm{L}$ for OBT. The screening performed allowed us to find 8 fungal strains belonging to Penicillium and Aspergillus gg., having various capacities to metabolize the benzothiazole and oxybenzothiazole. Unfortunately none of the tested strains was able to degrade the methabenzthiazuron, thus confirming the very high recalcitrance of this compound, although it is widely used in agriculture.

Most of the active fungal strains were producing two hydroxylated products resulting from BT oxidation (OBT and 2,6-dihydroxybenzothiazole) that were previously identified in the case of Rhodococcus strains [8]. Only on BT decomposition with Penicillium sp.24 fungi, the largest number (3) and quantities of metabolites were found, which points out indirectly at the broad spectrum of oxydoreductases of the strain in question. In this case, one new metabolite corresponding to the cleavage of the thiazole ring has been detected. It can be noted that the strain Penicillium sp.24 was previously shown to degrade triazine derivatives (MD Patent Application Nr.2007-0198). Also, it was proven that the spores of fungi show a higher activity in comparison with resting mycelium of active strains. However, BT and OBT degradation with fungi g.Penicillium will not result in the complete mineralization of xenobiotics, and BT/ OBT degradation rate only reached $60 \%$ after $96 \mathrm{~h}$, thus indicating the probable toxicity of the metabolites and/or the xenobiotic itself [11].

At the same time with the screening and comparison of a large number of microbial strains towards their capability to metabolise benzothiazole derivatives, we investigated the pathway of aminobenzothiazole (ABT) decomposition by R.rhodochrous OBT18 bacteria, which was selected due to its resistance to UV irradiation and to high degrading efficiency. Generally, the elimination of benzothiazole derivatives is extremely difficult when biotic or abiotic processes are used alone, so we propose to combine both photo-destruction (using Fe as photo-activator) and biodegradation (using bacteria) processes. For this purpose, a specific Photo-bioreactor was set-up to perform bio- and photo-destruction under the same conditions, and also simultaneously.

Direct photolysis did not show any degradation on the molecule since the molecule does not absorb in the solar spectrum, but degradation was observed both in the presence of bacteria, light and an iron complex acting as photoinducer (Fig.5). In combined systems with FeNTA and resting bacterial cells the destruction of ABT was very fast 


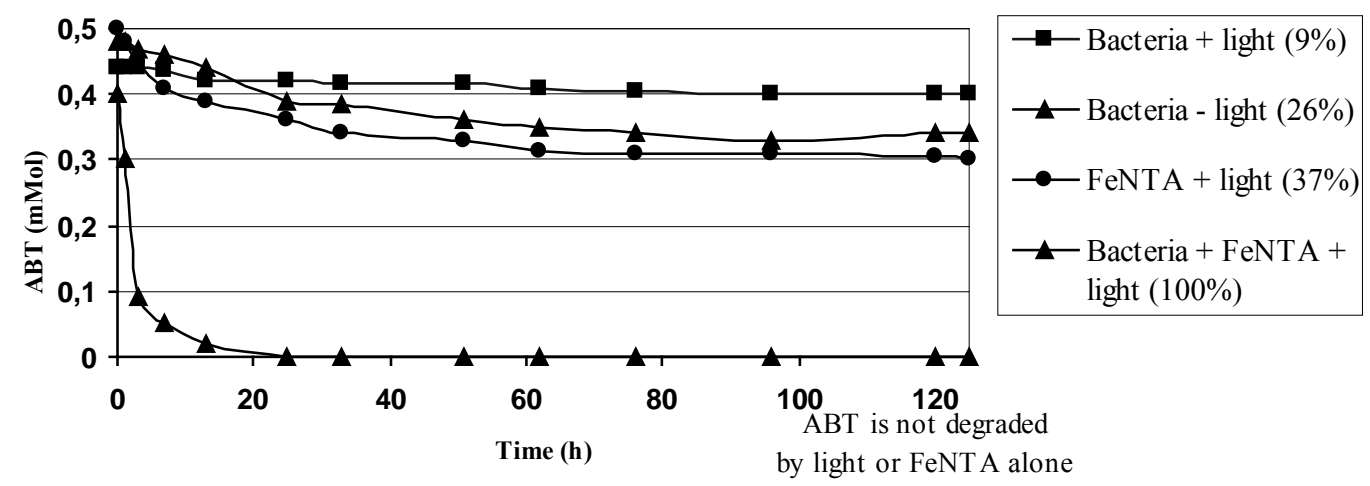

Fig. 5. ABT degradation under different conditions, 125 hours of incubation with R.rhodochrous OBT 18.

(total mineralization in 30 hours) and does not depend on the presence or absence of light. We can note that the effect of combination "FeNTA + R.rhodochrous cells \pm light" $(100 \%)$ is highly superior to simple sum of each factor taken separately.

Generally, the FeNTA complex - NTA for nitrilotriacetic acid - are efficient at neutral pH used for microbial incubations and are a good model of iron complexes present in organic natural matter. In our experiments, the addition of FeNTA to a simple system "R.rhodochrous \pm light" produces a very important synergetic effect [12]. It is already known that iron complexes have a photoinductive role in transformation of organic compounds, such as 4-chlorophenol [13]. Also, it is known that oxygenases involved in pollutant degradation usually contain Fe in their active site [14]. However, the iron activation of the organic compounds metabolizing processes, specifically ABT, is still unknown for aerobe bacteria; it is thus likely that iron from the FeNTA complex is taken by the cells leading to an activation of these enzymes. Surveying in situ of FeNTA/NTA in the presence of bacterial cells by NMR spectroscopy led to the schematic presentation of the mechanism of iron involvement in bacterial metabolism (Fig.6).

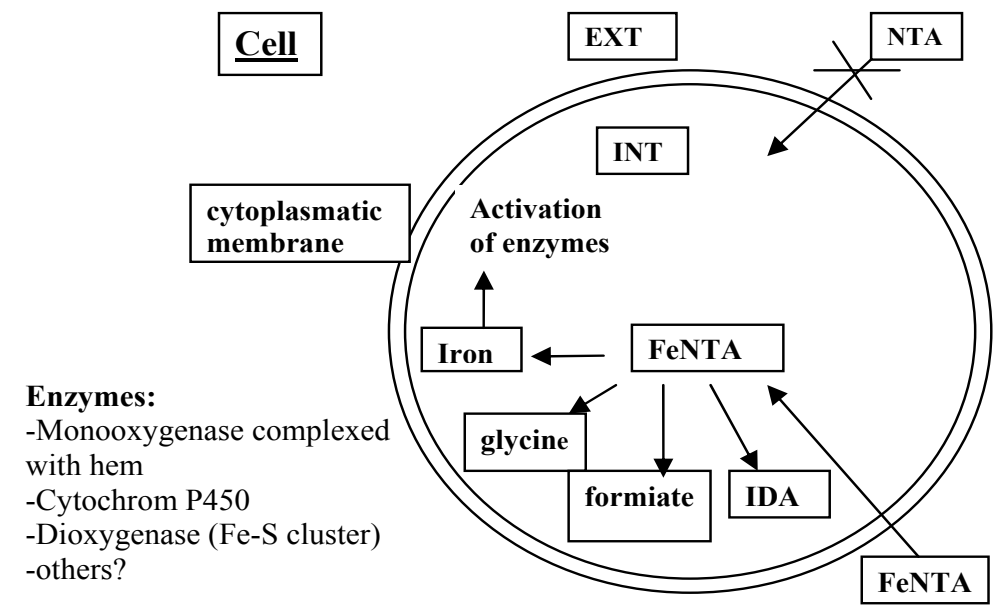

Fig. 6. Involvement of iron in bacterial metabolism [12].

Systematically, under all the conditions tested, 2-amino-6-hydroxybenzothiazole (6OH-ABT) was identified by NMR as the major intermediate of biotic decomposition of ABT. However, microorganisms involved in biodegradation mechanisms are not usually found as free cells. They can be naturally entrapped or attached to matrices and form biofilms in natural waters because of extracellular polymers they secrete themselves, or aggregates such as flocks in water treatment plants. Compared with free suspended cells, immobilized cells (IC) exhibit tolerance to toxic substances, enhance fermentation productivity, present more biological and physical stability and are re-usable.

Experiments were carried out to compare both ABT biodegradation pathway and the efficiency of the process conducted by free and Ca-alginate immobilized R.rhodochrous cells. In both systems, the biodegradation of ABT is more efficient in the absence of light, showing that alginate does not finally bring complete protection to the cells. By considering the adsorption effect of ABT on alginate beads, similar degradation rates were observed in both IC and free cell systems.

The positive effect of FeNTA on ABT degradation is observed with immobilized cells in a similar way that it was shown with free cells. This feature is very important regarding environmental context. Indeed FeNTA is considered as a 
good model of iron natural matter complexes existing in surface waters, moreover, NTA, used as domestic detergent, is very present in water treatment plants [15]. Thus, FeNTA could activate bacteria which can be in the form of immobilized cells (biofilms) in this environment [16].

In conclusion, the research on ABT decomposition have shown that the combination of FeNTA and free resting cells of R.rhodochrous in the presence or in the absence of light is still the most effective and assures $100 \%$ degradation of ABT in the first 21 hours of experiment. This result is very promising for improving the transformation of pollutant in water, and to apply them to a large number of benzothiazole derivatives.

\section{Experimental}

The objects of study were water solutions of Benzothiazole, 2-hydroxybenzothiazole, Methabenzthiazuron, and 2-aminobenzothiazole, purchased from Aldrich Ltd (Gillingham, Kent, UK).

Photodegradation: As a photodestruction catalyst, 1,0 mMol Fenton reagent was used, including hydrogen peroxide $\left(\mathrm{H}_{2} \mathrm{O}_{2}\right)$ and especially prepared solution of potassium trioxaloferrate (III) $\left(\mathrm{K}_{3}\left[\mathrm{Fe}\left(\mathrm{C}_{2} \mathrm{O}_{4}\right)\right]_{3} \cdot 3 \mathrm{H}_{2} \mathrm{O}\right)(\mathrm{PTOF})$, which possesses acceptability to light. Under UV-irradiation, in dependence on the amount of light adsorbed, iron (III) ions will oxidize the oxalic ions to carbonic ones, thus being transformed into the two-valence state. Further, during the interaction with $\mathrm{H}_{2} \mathrm{O}_{2}, \mathrm{Fe}(\mathrm{II}) / \mathrm{Fe}$ (III) will exert the photocatalytic effect, resulting in the series of redox-processes running in accordance with either radical-chain or ion-molecular mechanism, with the formation of free radicals $\left(\mathrm{OH}^{*}\right.$, $\mathrm{HO}_{2}^{-}, \mathrm{O}_{2}{ }^{-}$etc). [17]:

$$
\begin{array}{ll}
\mathrm{Fe}^{2+}+\mathrm{H}_{2} \mathrm{O}_{2} \rightarrow \mathrm{Fe}^{3+}+\mathrm{OH}^{\cdot}+\mathrm{OH}^{-} ; & \mathrm{Fe}^{2+}+\mathrm{OH}^{\cdot} \rightarrow \mathrm{Fe}^{3+}++\mathrm{OH}^{-} \\
\mathrm{OH}^{*}+\mathrm{H}_{2} \mathrm{O}_{2} \rightarrow \mathrm{HO}_{2}+\mathrm{H}_{2} \mathrm{O} ; & \mathrm{Fe}^{2+}+\mathrm{HO}_{2} \rightarrow \mathrm{Fe}^{3+}+\mathrm{HO}_{2}^{-} \\
\mathrm{Fe}^{3+}+\mathrm{HO}_{2} \rightarrow \mathrm{Fe}^{2+}+\mathrm{O}_{2}+\mathrm{H}^{+} ; & \mathrm{Fe}^{3+}+\mathrm{O}_{2}^{--} \rightarrow \mathrm{Fe}^{2+}+\mathrm{O}_{2} .
\end{array}
$$

The dispersion of $\mathrm{TiO}_{2}$ (OCЧ 7-3, manufactured at «Krasny khimik», SPtb Russia) was used, which represent a mixture of almost equal proportions of anatase and ruthyl crystalline forms. The amount of $\mathrm{TiO}_{2}$ introduced made 1 $\mathrm{g} / \mathrm{dm}^{3}$. OBT concentration in solution was detected using HPLC purchased from Agilent Technology at the $15 \mathrm{x} 3 \mathrm{~mm}$ column with the inverse $C_{18}$ phase, in the acetonytril: water system (25:75), rate flow was $1 \mathrm{ml} / \mathrm{min}$, UV detector - 265 nm.

The DRP-240 UV-lamps (2) used had the power capacity of $15-20 \mathrm{Wt} / \mathrm{m}^{2}$ within the wavelength range 200-400 $n m$.

Biodegradation: Strains from the collection of laboratory of Xenobiotransformation (Institute of Microbiology and Biotechnology, Academy of Sciences of Moldova), and bacterial strain Rhodococcus rhodochrous OBT18 from LSEESIB (Blaise Pascal University, France) were studied.

The verification of BTs transformation by fungi was made by cultivating in a liquid mineral medium E-8: $\left(\mathrm{NH}_{4}\right)_{2} \mathrm{HPO}_{4}-1.5 \mathrm{~g}, \mathrm{KH}_{2} \mathrm{PO}_{4}-0.7 \mathrm{~g}, \mathrm{NaCl}-0.5 \mathrm{~g}, \mathrm{MgSO}_{4} \times 7 \mathrm{H}_{2} \mathrm{O}-0.8 \mathrm{~g}$, and $\mathrm{H}_{2} \mathrm{O} 1 \mathrm{~L} ; \mathrm{pH}-5.5-5.7$ [11]. The preliminary study of BTs fungal degradation was carried out by GC ("Tsvet-500M" with the detector of constant recombination rate), after extraction of BTs/metabolites from the culture liquid with ethyl acetate [8].

ABT transformations by rhodococci were studied in "resting cells" experiments with free and immobilized cells by HPLC, NMR and mass-spectrometry methods. Cell immobilization was performed by entrapping in calcium alginate matrices $(4.17 \% \mathrm{w} / \mathrm{v})$. The resting or immobilized cells were incubated with $0.5 \mathrm{mMol}$ ABT in $500-\mathrm{mL}$ Erlenmeyer flaks at $28^{\circ} \mathrm{C}$ under agitation $(200 \mathrm{rpm})$ in the presence or the absence of light in the Photo-bioreactor. The concentration of FeNTA complex was $1 \mathrm{mMol}$. The negative controls lacking substrate or cells were incubated under the same conditions.

HPLC analyses were performed using a Waters 600E chromatograph fitted with a reversed-phase column (Interchrom Nucleosil $\mathrm{C}_{18} ; 5 \mu \mathrm{m}, 250$ by $4.6 \mathrm{~mm}$ ) at room temperature. The mobile phase was acetonitrile-water (20/80, $\mathrm{v} / \mathrm{v}$ ), with a flow rate of $1 \mathrm{~mL} / \mathrm{min}$. Detection was performed with a Waters $486 \mathrm{UV}$ detector set at 295 nm [8]. NMR spectroscopy: all ${ }^{1} \mathrm{H},{ }^{13} \mathrm{C}$ NMR spectra were recorded on a Bruker Avance 500 spectrometer at $300.13 \mathrm{MHz}$ and 75.47 $\mathrm{MHz}$ respectively, at $298 \mathrm{~K}$ using a 5 -mm triple-tuned ${ }^{1} \mathrm{H}-{ }^{13} \mathrm{C}-{ }^{15} \mathrm{~N}$ probe equipped with a z-gradient coil. ${ }^{1} \mathrm{H}$ and ${ }^{13} \mathrm{C} 90^{\circ}$ pulse lengths were 7.5 , and $8.6 \mu$ s, respectively.

\section{Acknowledgements}

This research was performed in the frames and with the financial support of the INTAS Project Ref. Nr. 05-1047596.

\section{References}

[1] Schiavello M. Photoelectrochemistry, Photocatalysis, Photoreactors. Fundamentals and Developments. D.Reidel Publ., Dordrecht, 1985, 632 p.

[2] Mailhot, G.; Hykrdova, L.; Jirkovsky, J.; Lemr, K; Grabner, G.; Bolte, M. Appl. Catal. B: Environ. 2004, 50, 25-35. 
[3] Skryabin, G.; Golovleva, L. Microorganisms in organic chemistry; Nauka: Moskva, 1976; 9-33.

[4] Bunescu, A.; Besse-Hoggan, P.; Sancelme, M.; Cincilei, A.; Mailhot, G.; Delort, A.-M., Microbial degradation of 2-benzothiazole derivatives: A Review. Wang, B.Y., Eds. Environmental Biodegradation Research Focus; Nova Publishers: New York, 2008; 159-187.

[5] Amato, J.R.; Mount, D.I.; Durhan, E.J.; Lukasewycs, M.T. Environ.Toxicol.Chem., 1992, 11, $209-217$.

[6] Gaja, M.A.; Knapp, J.S. J.of Appl.Microbiol., 1997, 83, 327-334.

[7] De Wever, H.; Vereecken, K., Stolz, A; Verachtert, H. Appl. Environ. Microbiol., 1998, 64, 3270-3274.

[8] Besse, P.; Combourieu, B.; Boyse, G.; Sancelme, M.; De Wever, H.; Delort, A.M. Appl. Environ. Microbiol., 67, 2001, 1412-1417.

[9] Liqiang, Z.; Xiaojun, S.; Weimin, C.; Zilli, X.; Yaoguo, D. J .Phys. Chem. Solids, 2003, 64, 615-623.

[10] Banerjee, S.; Gopal, J.; Muraleedharan, P.; Tyagi, A.K.; Raj, B. Current Science, 2005, 90, 10, 1378-1383.

[11] Cincilei, A.; Dragalin, I; Tolocichina, S., Delort, A.-M., Besse, P. Book of Proc. Int.Conf. "Biology and Ecology of Fungi in Natural Ecosystems", Minsk, 2004; 288-292.

[12] Bunescu A., Ph.D. Thesis Nr.1725, Blaise Pascal University, Clermont-Ferrand (France), 2006, 203 p.

[13] Abida O., Ph.D. Thesis Nr.1635, Blaise Pascal University, Clermont-Ferrand (France), 2005, 212 p.

[14] Ferraroni, M.; Solyanikova, I.; Kolomytseva, M. J.Biol.Chem., 2004, 279, 27646-27655.

[15] Egli, T. J. Biosc. Bioeng., 2001, 92, 89-97.

[16] Junter, G.A.; Jouenne, T. Biotechnol. Adv., 2004, 22, 633-658.

[17] Walling, C. Acc. Chem.Res., 1975, 8, 125-131. 